\title{
Pattern and correlates of cyberbullying victimization among Egyptian university students in Beni-Suef, Egypt
}

\author{
Original \\ Article \\ Ahmed E. Arafa, Shaimaa A. Senosy \\ Department of Public Health and Community Medicine, Faculty of Medicine, Beni-Suef \\ University, Egypt
}

\begin{abstract}
Background: The expansion of the online environment has unveiled many cyber risks and potentials for abuse such as cyberbullying. Cyberbullying carries many negative psychological impacts that affect mainly young people.

Aim: The objective of our study is to explore the of cyberbullying victimization among Egyptian university students in Beni-Suef and investigate factors correlating with it.

Materials and Methods: In this cross-sectional study, a multi-stage random sampling was used to include a total of 6740 students from all grade levels in all faculties $(n=28)$ of Beni-Suef University. After 4 focus group discussions, a self-administered questionnaire was designed for data collection. The questionnaire comprised three sections including questions about selected socio-demographic characteristics, exposure to cyberbullying in the past 6 months, and factors associated with victimization.

Results: Almost half of our students (48.2\%) reported experiencing cyberbullying victimization in the past 6 months. Female students, students living in urban areas and those who spent more hours using the internet reported more exposure $(\mathrm{p}<0.001)$. Harassment was the main type stated by females $(79.8 \%)$ while flaming was excessively reported by males $(51.8 \%)$. Students responded mostly by anger $(63.1 \%)$, hatred $(23.2 \%)$ and sorrow $(22.6 \%)$ towards the worst victimization incidents.

Conclusion: Cyberbullying victimization is highly prevalent amongst university students in Beni-Suef and female students are more vulnerable to exposure, Implementing anti-cyberbullying programs tailored for university students will be a major step. Such programs should include anti-cyberbullying policies and materials, and provision of guidance for students, their parents and their teaching staff.
\end{abstract}

Received: 22 January 2017, Accepted: 25 April 2017

Key Words: Cyberbullying, victimization, harassment, university students, social networking.

Corresponding Author: Shaimaa A. Senosy, MD, Beni-Suef, 62511 Mukbel, Egypt Tel.: +20 109 940 8780, E-mail: shoshoahmed80@yahoo.com,shaymaa.sayed@med.bsu.edu.eg

ISSN: 0013-2446, Vol. 92, No.2

\section{INTRODUCTION}

Almost one of two persons worldwide is using the internet and one billion households have internet access. Developing countries are home for more than 2.5 billion internet users ${ }^{[1]}$. In Egypt, the digital society expanded markedly from 12.3 million internet users in 2009 to 29.84 million users in 2016 ${ }^{[2]}$. In terms of worldwide Facebook subscriptions, Egypt is ranked 17th, as $98 \%$ of internet users have Facebook accounts; $52 \%$ of them are younger than 24 years. Half of the Egyptian internet users have twitter accounts, whereas a third of them are active on Instagram $^{[3]}$.

Communication, getting information, accessing educational materials, and enhancing social support are among many established benefits of social networking ${ }^{[3-5]}$. However, many negative implications have been associated with social media platforms as cybercrime, exposure to inappropriate material, and cyberbullying ${ }^{[4-6]}$.

Cyberbullying can be defined as intentional aggression through electronic routes, such as text messages, e-mails, chat rooms, online games, and social websites ${ }^{[3,7]}$. In comparison with traditional bullying, cyberbullying has many unique characteristics that boost its harmful effects, including the inability to avoid bullying, presence of larger and more potential audience, the continuity of bullying regardless of time or place, and the anonymity of perpetrator in many occasions ${ }^{[8]}$. These unique criteria lead to power imbalance between the perpetrators and their targets resulting in cybervictimization ${ }^{[7]}$.

Numerous subtypes of cyberbullying have been reported, including 'flaming', which is intense and hostile arguments that regularly include insulting; 'outing' which includes exposure of secrets or sensitive material; 'denigration and mockery', which involves using hurtful statements to put down the victim; 'harassment', which involves unsolicited communications or interactions; 'threating and intimidation' by sending terrifying or terrorizing messages; and 'exclusion' by singling out from online groups or chat rooms ${ }^{[4,9]}$. 
Rates of cyberbullying victimization in young people cannot be easily tracked owing to lack of agreed definitions over cyberbullying and differences in the targeted populations. In addition, researchers applied different designs and tested the victimization during different periods. Accordingly, the published rates varied widely; in a study involving 40 countries $^{[10]}$, a rate of $3 \%$ was reported among adolescents, whereas a recent study (2016) in Malaysia ${ }^{[9]}$ reported a rate of $86 \%$ among high school students.

Many psychological effects have been associated with cyberbullying ranging from emotional distress, lack of concentration ${ }^{[11,12]}$, absenteeism, and poor academic achievement ${ }^{[7,13]}$ up to somatic disorders, depression, and suicidal ideation ${ }^{[14,15]}$.

Considering the fact that one-third of Egyptian population is using the internet and youths represent the vast majority of users ${ }^{[2]}$, our study was conducted to detect the frequency of cyberbullying victimization among BeniSuef University students in the past 6 months, explore its pattern, and investigate the possible factors correlating with victimization.

\section{MATERIALS AND METHODS}

This cross-sectional survey was conducted in BeniSuef University on 6740 students attending the faculties of the university between September and December 2016. Beni-Suef University is one of the largest educational institutions in Upper Egypt with more than 45000 students registered in 28 faculties: nine faculties of health and medical sciences; seven faculties of natural sciences, engineering, and computer sciences; and 12 faculties of humanities and social and behavioral sciences.

\section{Sampling}

We obtained formal statistics from the university administration about the number of students registered in each faculty distributed by grade level. The least sample size from each faculty was calculated separately because the numbers of students registered in each faculty varied widely. Besides, although Beni-Suef University includes large number of faculties, most of these faculties have relatively small number of students. In addition, many faculties did not include all academic years as they are new faculties. Epi-Info version 7 Stat Calc, [Center for Disease Control and Prevention (CDC), World Health Organization (WHO)], Atlanta, Georgia (USA) was used supposing exposure rate of $50 \%$, confidence level of $90 \%$, margin of error of $5 \%$, and nonresponse rate of $20 \%$. All the minimum sample sizes estimated for each of the 28 faculties were summed to give a total of 1800 students. For each faculty, the minimal size was distributed on the different grades using the proportional allocation method. As many students were eager to participate in the study, the sample size was raised to approximately three-folds keeping the same weights $(n=6740)$. Then all the students from all faculties were treated as one pool in the analysis. Only students with no internet access were excluded from the study.

A total of 7500 students were targeted to participate in the study; of them 6782 filled in the questionnaire giving a response rate of $90.4 \%$, and then 42 questionnaires were excluded because of the incomplete data about exposure to cyberbullying, giving a total of 6740 completed questionnaires. Response rate was higher in female students and in students attending medical faculties. Students who refused to participate justified that they did not see benefits of the study or they did not like to share personal data.

\section{Focus group discussions}

Before commencing the fieldwork, four separate focus group discussions (FGD), including students from different faculties, were held to explore the opinion of students about the nature of cyberbullying, its contributing factors, and its consequences. Each FGD included 8-14 students and lasted for almost $60 \mathrm{~min}$.

\section{The questionnaire}

For data collection, a self-administrated Arabic language questionnaire with three sections was designed. Section I included sociodemographic data and hours of internet use per day. Section II questioned about whether the student was exposed to cyberbullying or not in the past 6 months, frequency of exposure, and types of cyberbullying the student experienced. Six types of cyberbullying were given as choices where the student could pick more than one choice: flaming, outing, denigration and mockery, harassment, threating and intimidation, and exclusion. Definition of cyberbullying and description of its types were included in this section. Only students who reported cyberbullying could move to section III that included questions about type of the worst incident the student fell victim to in the past 6 months and the psychological consequences of this incident, namely, sorrow, disappointment, loneliness, anger, hatred, and fear.

Before administering the questionnaire, a pilot study on 200 medical students was conducted to test the validity and reliability of questionnaire. The Cronbach's $\alpha$ for reliability was 0.82 , whereas content validity was judged by a professor of public health and a professor of psychology. As there were no modifications on the questionnaire after the pilot study and the results were largely close to the final findings, they were included in the final sample.

\section{Ethical considerations}

After getting institutional approvals, the Faculty of Medicine, Beni-Suef University Research Ethics Committee, approved the protocol. The students were informed of the purpose of the study and its consequences with confirmation of confidentiality of data. All participants had the right not to participate in the study. 


\section{Statistical analysis}

Data were analyzed using the software, statistical package for the social sciences (SPSS) version 18 (SPSS Inc., Chicago, Illinois, USA). Frequency distribution as percentage and descriptive statistics in the form of mean and SD were calculated. $\chi^{2-T e s t, ~} t$-test, and correlations were done when indicated. $P$ values of less than 0.05 were considered significant.

\section{RESULTS}

The study included 6740 students: 2035 (30.5\%) from health and medical sciences faculties; 986 (14.6\%) from natural sciences, engineering, and computer sciences faculties; and 3701 (54.9\%) attending faculties of humanities and social and behavioral sciences. The mean age of the participating students was $20 \pm 1.4$ years (18-24 years). of the total students, $3609(54.8 \%)$ were living in urban suburbs, whereas $2982(45.2 \%)$ were living in rural ones. The students' daily internet use ranged between 10 min and $16 \mathrm{~h}$, with a mean duration of $5.5 \pm 3.8 \mathrm{~h}$ (Table 1$)$.

Table 1: Socio-demographic characteristics of the participating students, Beni-Suef University, Egypt, 2016

\begin{tabular}{|c|c|c|c|}
\hline Characteristics & $\begin{array}{l}\text { Male } \\
\mathrm{n}=2297 \\
\mathrm{n}(\%)\end{array}$ & $\begin{array}{l}\text { Female } \\
\mathrm{n}=4443 \\
\mathrm{n}(\%)\end{array}$ & $\begin{array}{l}\text { Overall } \\
\mathrm{n}=6740 \\
\mathrm{n}(\%)\end{array}$ \\
\hline $\begin{array}{l}\text { Age }(\text { Mean } \pm \text { SD }) \text { ys } \\
(n=6721)\end{array}$ & $20.2 \pm 1.4$ & $19.9 \pm 1.3$ & $20 \pm 1.4$ \\
\hline \multicolumn{4}{|l|}{$\begin{array}{l}\text { Residence } \\
(\mathrm{n}=6591)\end{array}$} \\
\hline Urban & $1211(53.7)$ & $2398(55.3)$ & 3609 (54.8) \\
\hline Rural & $1046(46.3)$ & $1936(44.7)$ & $2982(45.2)$ \\
\hline \multicolumn{4}{|l|}{$\begin{array}{l}\text { Faculties } \\
(n=6740)\end{array}$} \\
\hline Medical Scs & $646(28.1)$ & $1407(31.7)$ & $2053(30.5)$ \\
\hline Natural Scs & $620(27)$ & $366(8.2)$ & $986(14.6)$ \\
\hline Humanities & 1031(44.9) & $2670(60.1)$ & $3701(54.9)$ \\
\hline Internet use $($ Mean \pm SD) hs/d $(n=6655)$ & $5.6 \pm 3.5$ & $5.5 \pm 4$ & $5.5 \pm 3.8$ \\
\hline
\end{tabular}

Scs: Sciences

In the FGD, students defined cyberbullying as 'putting down someone in public status on Facebook or twitter', 'naming others with bad descriptions', 'harassment using sexual words, suggestions or explicit content', 'sending nasty e-mails' or 'hacking e-mails and accounts'.

Most students attributed cyberbullying to 'immorality of perpetrators', 'social background of the bullies', or 'the political and economic turmoil', whereas others commented by 'it is normal'.

Students also expected higher rates of cyberbullying victimization instances among females because of sexual harassment. Female students described the frequency of cyber-harassment by 'it happens every day' or 'not uncommon'. A male student added 'girls become afraid of the reaction, and they cannot defend themselves'. A female student thought that 'females are easy prey, they are passive', and 'offenders realize that they will run with their acts' she added. On the contrary, a male student suggested that 'males and females are equally bullied but males do not easily admit being victims', describing that as 'a matter of dignity'.

Some students considered cyberbullying a 'demographic problem'; 'cyberbullying is uncommon in rural areas because villages are small and parents of perpetrators can be reached easily; then a big problem can happen'. A student said 'in rural areas, online problems will turn into problems on real world'. However, a student justified that difference by 'simply, rural residents are more polite and still respect moral values'.

When students were asked about who would be more vulnerable between students attending medical faculties or students attending social ones, and almost all students agreed that the second group is more prone to be cyberbullied. The students' comments revolved around 'medical students do not have time to socialize' or 'medical students are more serious'.

Regarding the psychological effects of cyberbullying, few students responded with 'temporary sorrow', 'hatred and desire to revenge', or 'feeling unsafe', whereas others replied with 'nothing'. Anger was the response of many attending students ' $\mathrm{I}$ do not know the aggressor and I do not know how to behave; this drives me mad' or 'anger is a normal reaction'.

Nearly half of the students $(3247,48.2 \%)$ reported exposure to cyberbullying during the past 6 months; most of those students were victimized more than once. Female students were much more likely and more frequently to be cyberbullied $(P<0.05)$. Students residing in urban areas 
and students in natural sciences and humanities faculties were more vulnerable to be cyberbullied $(P<0.05)$. Those students also reported being cyberbullied more frequently $(P<0.05)$. Spending more hours per day using internet was associated with both exposure and frequency of exposure to cyberbullying instances $(P<0.05)$. However, the age of students was neither associated with exposure to cyberbullying nor with the frequency of exposure $(P>0.05)$ (Tables 2 and 3).

Table 2: Factors correlated with exposure to cyberbullying during the past 6 months among the participating students, Beni-Suef University, Egypt, 2016

\begin{tabular}{|c|c|c|c|}
\hline Characteristics* $^{*}$ & $\begin{array}{l}\text { Exposed } \\
n=3247 \\
n(\%)\end{array}$ & $\begin{array}{l}\text { Not-exposed } \\
n=3493 \\
n(\%)\end{array}$ & $\mathrm{P}$ value + \\
\hline Age $($ Mean \pm Sd) ys $(n=6721)$ & $20 \pm 1.3$ & $20 \pm 1.4$ & 0.909 \\
\hline $\begin{array}{l}\text { Sex } \\
(n=6740)\end{array}$ & & & $<0.001$ \\
\hline Male & $897(39.1)$ & $1400(60.9)$ & \\
\hline Female & $2350(52.9)$ & $2093(37.1)$ & \\
\hline $\begin{array}{l}\text { Residence } \\
(\mathrm{n}=6591)\end{array}$ & & & $<0.001$ \\
\hline Urban & $1864(51.6)$ & $1745(48.4)$ & \\
\hline Rural & $1304(43.7)$ & $1678(56.3)$ & \\
\hline $\begin{array}{l}\text { Faculties } \\
(n=6740)\end{array}$ & & & $<0.001$ \\
\hline Medical Scs & $887(43.2)$ & $1166(56.8)$ & \\
\hline Natural Scs & $527(53.4)$ & $459(46.6)$ & \\
\hline Humanities & $1833(49.5)$ & $1868(50.5)$ & \\
\hline Internet use $($ Mean \pm Sd $)$ hs/d $(n=6655)$ & $6.3 \pm 4$ & $4.8 \pm 3.5$ & $<0.001$ \\
\hline
\end{tabular}

Scs: Sciences + Chi squared test

Table 3: Factors correlated with frequency of exposure to cyberbullying during the past 6 months among the participating students, Beni-Suef University, Egypt, 2016

\begin{tabular}{|c|c|c|c|}
\hline Characteristics $^{*}$ & $\begin{array}{c}\text { Exposed once } \\
n=1110 \\
n(\%)\end{array}$ & $\begin{array}{c}\text { Exposed more than } \\
\text { once } n=2137 \\
n(\%)\end{array}$ & $\mathrm{P}$ value + \\
\hline Age $($ Mean \pm Sd) ys $(n=3238)$ & $20 \pm 1.3$ & $20 \pm 1.3$ & 0.733 \\
\hline $\operatorname{Sex}(n=3247)$ & & & $<0.001$ \\
\hline Male & 403 (44.9) & $494(55.1)$ & \\
\hline Female & $707(30.1)$ & 1643 (69.9) & \\
\hline Residence $(n=3168)$ & & & 0.043 \\
\hline Urban & $606(32.5)$ & $1258(67.5)$ & \\
\hline Rural & $463(35.5)$ & $841(64.5)$ & \\
\hline $\begin{array}{l}\text { Faculties } \\
(n=3247)\end{array}$ & & & $<0.001$ \\
\hline Medical Scs & $312(28.1)$ & $575(26.9)$ & \\
\hline Natural Scs & $196(17.7)$ & $331(15.5)$ & \\
\hline Humanities & $602(54.2)$ & $1231(57.6)$ & \\
\hline Internet use $($ Mean \pm Sd $)$ hs/d $(n=3211)$ & $5.7 \pm 3.9$ & $6.5 \pm 4$ & $<0.001$ \\
\hline
\end{tabular}

Scs: Sciences + Chi squared test

Multivariate logistic regression for the factors associated with exposure to cyberbullying and the frequency of this exposure by univariate analysis (sex, residence, faculties, and duration of internet use) showed that all these variables were potential contributing factors to cyberbullying victimization $(P<0.05)$, and only residence was excluded from the potential risk factors contributing to the frequency of exposure to cyberbullying $(P>0.05)$.
Among different instances of cyberbullying victimization, flaming was the most commonly reported type among male students $(51.8 \%)$ followed by denigration and mockery (38.8\%), and exclusion $(27 \%)$. The nature of victimization in female students was totally different, as most females $(79.8 \%)$ reported harassment, whereas flaming came second $(20.5 \%)$ and then denigration and mockery (20\%). In general, harassment, flaming, and 
denigration and mockery were the most common types of cyberbullying victimization, according to the students' reports. Apart from harassment, male students reported significantly higher rates of exposure to all types of cyberbullying than female students $(P<0.05)$ (Table 4$)$.

Table 4: Types of cyberbullying during the past 6 months reported by the participating cyberbullied students, Beni-Suef University, Egypt, 2016

\begin{tabular}{lllll}
\hline Types & $\begin{array}{l}\text { Male } \\
\mathrm{n}=897 \\
\mathrm{n}(\%)\end{array}$ & $\begin{array}{l}\text { Female } \\
\mathrm{n}=2350 \\
\mathrm{n}(\%)\end{array}$ & $\begin{array}{l}\text { Overall } \\
\mathrm{n}=3247 \\
\mathrm{n}(\%)\end{array}$ & P value+ \\
\hline Flaming & $465(51.8)$ & $481(20.5)$ & $946(29.1)$ & $<0.001$ \\
Outing & $153(17.1)$ & $181(7.7)$ & $334(10.3)$ & $<0.001$ \\
Denigration & $348(38.8)$ & $469(20)$ & $817(25.2)$ & $<0.001$ \\
Harassment & $131(14.6)$ & $1876(79.8)$ & $2007(61.8)$ & $<0.001$ \\
Threating & $120(13.4)$ & $199(8.5)$ & $319(9.8)$ & $<0.001$ \\
Exclusion & $242(27)$ & $207(8.8)$ & $449(13.8)$ & $<0.001$ \\
\hline
\end{tabular}

+ Chi squared test

Regarding the type of worst incident the cyberbullied students experienced during the past 6 months, flaming, denigration and mockery, and exclusion were the most frequently reported types in male students $(35.2,24.6$, and $12.3 \%$, respectively), compared with harassment, flaming, and denigration and mockery in female students (64.2,

Table 5: Types of the worst incident of cyberbullying during the past 6 months reported by the participating cyberbullied students, Beni -Suef University, Egypt, 2016

\begin{tabular}{lllll}
\hline Types & $\begin{array}{l}\text { Male } \\
\mathrm{n}=897,(\%)\end{array}$ & $\begin{array}{l}\text { Female } \\
\mathrm{n}=2350,(\%)\end{array}$ & $\begin{array}{l}\text { Overall } \\
\mathrm{n}=2347,(\%)\end{array}$ & P value $^{\mathrm{a}}$ \\
\hline Harassment & $89(9.9)$ & $1509(64.2)$ & $1598(49.2)$ & $<0.001$ \\
Flaming & $316(35.2)$ & $258(11)$ & $574(17.7)$ & $<0.001$ \\
Denigration & $221(24.6)$ & $248(10.6)$ & $469(14.4)$ & $<0.001$ \\
Exclusion & $110(12.3)$ & $100(4.3)$ & $210(6.5)$ & $<0.001$ \\
Outing & $90(10)$ & $109(4.6)$ & $199(6.1)$ & $<0.001$ \\
Threating & $71(7.9)$ & $126(5.4)$ & $197(6.1)$ & 0.005 \\
\hline
\end{tabular}

+ Chi squared test

Anger, hatred, and sorrow were the most common emotional responses to the worst incident students experienced in the previous 6 months $(63.1,23.2$, and $22.6 \%$, respectively). Compared with female students, male students were more likely to respond by sorrow, disappointment, anger,
11 , and $10.6 \%$, respectively). Again, harassment was the only type of cyberbullying victimization to be more reported among female students, whereas other types were significantly more worrisome for male students $(P<0.05)$ (Table 5). and hatred, whereas female students were more likely to react by fear $(P<0.05)$ (Table 6). Furthermore, most students expressed their anger toward harassment with no remarkable differences between male and female students in emotional responses $(P>0.05)$.

Table 6: Emotional responses to the worst incident of cyberbullying during the past 6 months reported by cyberbullied students, Beni-Suef University, Egypt, 2016

\begin{tabular}{lllll}
\hline Responses & $\begin{array}{l}\text { Male } \\
(\mathrm{n}=897, \%)\end{array}$ & Female $(\mathrm{n}=2350, \%)$ & Overall $(\mathrm{n}=2347, \%)$ & $P$ value \\
\hline Anger & $591(65.9)$ & $1457(62)$ & $2048(63.1)$ & 0.022 \\
Hatred & $295(32.9)$ & $457(19.4)$ & $752(23.2)$ & $<0.001^{* *}$ \\
Sorrow & $245(27.3)$ & $490(20.9)$ & $735(22.6)$ & $<0.001^{* *}$ \\
Fear & $60(6.7)$ & $460(19.6)$ & $520(16)$ & $<0.001^{* *}$ \\
Disappointment & $165(18.4)$ & $289(12.3)$ & $454(14)$ & $<0.001^{* *}$ \\
Loneliness & $32(3.6)$ & $86(3.7)$ & $118(3.6)$ & 0.498 \\
** Significant at P<0.001 & & &
\end{tabular}

\section{DISCUSSION}

Cyberbullying has been a topic of rising concern for internet users in the western world over the past decade. This 
victimization during the past 6 months. The wide variations in definitions and study designs used to assess cyberbullying resulted in obvious discrepancies in the rates of cyberbullying. For example, a study on high school students in Indonesia showed that the majority of students $(80 \%)$ reported cyberbullying victimization ${ }^{[9]}$. In a webbased survey, Juvonen and Gross ${ }^{[16]}$ reported that $72 \%$ of children 12-17 years experienced cyberbullying at least for once. On the contrary, rates of cyberbullying victimization did not exceed $5 \%$ in many studies ${ }^{[8,17]}$. The high frequency of cyberbullying among victimized students in our study is consistent with most literature studies in this concern ${ }^{[7,11,18]}$.

In addition, female students in our study reported significantly higher rates of cyberbullying victimization. Sex difference regarding victimization varied among studies, as Lindfors et al. ${ }^{[8]}$ and Kowalski and Limber ${ }^{[7]}$ recorded higher rates and frequencies of victimization in females, whereas a study conducted on Turkish university students revealed higher rates of victimization and also bullying among male students ${ }^{[19]}$. Other studies showed that males and females equally experienced cyberbullying ${ }^{[9,13,16]}$.

In general, harassment constituted the main bulk of both female and overall reported cyberbullying offences in our study. The results unveiled that $79.8 \%$ of the cyberbullied female students and $61.8 \%$ of all cyberbullied students experienced cyber-harassment at least once during the past 6 months, and harassment was the only instance of cyberbullying to be more frequent by far in female than in male students $(P<0.05)$

However, the striking rates of cyberbullying victimization among female students in our study should not be separated from the sphere of violence against women in general. According to the United Nations Statistical Commission, domestic, sexual and psychological violence offences against females are evident in Egypt ${ }^{[20]}$, and such acts are depressingly rising ${ }^{[21]}$. A previous report by the International Communication Association (2007) concluded that $30 \%$ of all internet traffic contains porn content, $88.2 \%$ of porn scenes include aggressive acts, and $94 \%$ of these acts are directed toward women ${ }^{[22]}$. Compared with males, female activists and bloggers receive sexrelated attacks particularly in male-dominated spaces ${ }^{[23]}$. Such cultural implications that lead to imbalance of social and relational powers between males and females may push females to the weaker side, create a female-hating environment, and make women always vulnerable ${ }^{[20]}$.

Another opinion suggests that females usually use internet for social purposes, whereas males spend their online time gaming. Subsequently, females' social networking behavior may make them more prone to experience cyberbullying ${ }^{[23]}$.
Previous studies concluded that females are more likely to be victims and bullies at the same time. Being less confrontational because of the cultural constraints, females resort to online bullying rather than participating in 'unladylike' traditional bullying. So, girls who suffer troubles with same-sex friends would use social networking to assert dominance over others, and the vicious circle continues $^{[24]}$.

In our study, frequency of internet use was associated with exposure to cyberbullying, which coincides with previous studies ${ }^{[23,25]}$. What is really worth pointing out is that the mean duration spent online daily, as reported by students, was almost $5.5 \mathrm{~h}$, and the cyberbullied students spent more than $6 \mathrm{~h}$ a day online. The long duration our students spend online supports recent suggestion of internet and social networking addiction among Egyptian university students ${ }^{[26]}$.

The relationship between cyberbullying victimization and age is inconsistent; a previous literature study showed negative correlation between age and cyberbullying exposure and frequency ${ }^{[7]}$, whereas others agreed with our findings and suggested no association at all ${ }^{[6,8,9]}$. However, the range of age in our sample (18-24 years) was relatively limited to show differences in exposure to cyberbullying.

Students residing in rural areas were less likely to be cyberbullied according to our results. This finding can be understood in the frame that rural areas in Egypt are closed communities, so perpetrators may not be able to keep their anonymity for long. Furthermore, unlike the westernized lifestyle enhancing independence in urban cities, rural communities still appreciate the role of parents who usually offer different kinds of social integration and support. Parents' intervention is thought to prevent cyberbullying victimization $^{[27]}$. A previous study by Haynie et al. ${ }^{[28]}$ concluded that parental warmth and support, which rural communities are famous for, could protect young people from falling as victims to cyberbullying.

In the current study, the rate and frequency of exposure to cyberbullying were significantly associated with studying in specific faculties, specifically humanities and behavioral and social sciences institutions. Students in these faculties usually use internet for socializing rather than studying, making them more vulnerable to be cyberbullied. On the contrary, medical students were the least to report cyberbullying victimization. Siegle ${ }^{[29]}$ stated that academically gifted students are less likely to bully and consequently less likely to be bullied. Besides, Saied et al.$^{[26]}$ found that $72 \%$ of the medical students in Egypt use internet mainly for academic purposes. This nature of internet use makes medical students spend less hours socializing and consequently makes them less prone to be cyberbullied. 
Our results also revealed that harassment was the most commonly reported type of cyberbullying victimization, later came flaming, especially among male students. In agreement, Safaria ${ }^{[9]}$ stated that most school students in Indonesia were subjected to harassment. The author concluded that exclusion, threatening, and outing were relatively uncommon. Hemphill and Heerde ${ }^{[30]}$ showed that cyber-harassment was not uncommon among young adults in Australian schools. Akbulut and Eristi ${ }^{[19]}$ stated that $81 \%$ of the victims in Turkey received harassment e-mails and $26 \%$ were cursed or insulted, whereas $25 \%$ of offenders admitted excluding or blocking others from online groups and chat rooms.

Beran and $\mathrm{Li}^{[13]}$ linked the high rates of cyberharassment and cyber-flaming with traditional bullying, as victims tend to retaliate against the aggressors by e-mailing them harassment and flaming statements, leaning to the anonymity secured by being behind computers. Henry and Powell ${ }^{[31]}$ considered online harassment or technologyfacilitated sexual violence a translation of the traditional violence against females, regardless of the route.

Furthermore, this study pointed to many emotional responses following cyberbullying victimization. Our results showed that anger was the most likely psychological effect felt by the cyberbullying offences. Sorrow, hatred, and disappointment were also common effects, whereas fear and loneliness were relatively uncommon. Research on cyberbullying has documented many hurtful psychological consequences that may last for long ${ }^{[1-15]}$.

In consistence with our findings, anger was a common response to exposure to cyberbullying in previous literature studies $^{[32-35]}$.

According to Olenik-Shemesh et al. ${ }^{[36]}$, loneliness and depressive mood were the main consequences of cyberbullying victimization in adolescents. Moreover, Price and Dalgleish ${ }^{[37]}$ who studied a sample of Australian young people under 25 years reported increased sadness and fear as well as low self-esteem and self-confidence among the students after being cyberbullied. Moreover, Jackson and Cohen ${ }^{[38]}$ concluded a solid association between loneliness and cyberbullying victimization. Recently, Larrañaga et al. ${ }^{[39]}$ reported loneliness and avoidant communication with family in cyber-victimized Spanish youths. Many studies also linked exposure to cyberbullying to depression or even suicidality ${ }^{[14,15]}$.

\section{LIMITATIONS}

This study poses some limitations. First, the present sample contained a higher proportion of female students than male students. As males and females usually show different patterns of exposure to cyberbullying, the overrepresentation of females in the present sample may hinder generalization to all Beni-Suef students. The sample included only university students, known to enjoy relatively higher socioeconomic level than their counterparts who do not attend higher education institutions, which may hinder the generalizability of results. Besides, the study included only cyber victims but not perpetrators nor cyber-bystanders. The conservative nature of Beni-Suef Governorate, where most of our students belong to, would underestimate the cyberbullying exposure and reporting rates. Finally, using a longitudinal research design might be more appropriate in detecting both the predictors and outcomes of cyberbullying.

\section{CONCLUSION AND RECOMMENDATIONS}

In addition to exploring rates of cyberbullying victimization among Egyptian university students, its patterns, and associations, our study carries many potential implications for research and practical actions. From a research view point, investigating the academic impacts of exposure to cyberbullying should be considered. Further studies have to stress on exploring the coping strategies used to counter-fight cyberbullying. Practically, students and their parents should be informed of the hazardous effects of exposure to cyberbullying. Implementing anticyberbullying programs tailored for university students will be a major step. Such programs should include anticyberbullying policies and materials and provision for guidance of students, their parents, and their teaching staff.

\section{ACKNOWLEDGEMENTS}

Medical Students' team: Zidan M.A., Abdeltawwab T.M., Azizeldin A.A., Abdelazeem R.N., Hefzy F.N., Hassan H.R., Abdo Y.T., Abdelaziz H.A., Mohamed A.K., Khalil E.M., Dardir M.S., Hindy A.S., Ali N.H., Yaseen E.M., Mohammed O.R., Safwat H.M., Gamal Eldin E.M.

\section{CONFLICT OF INTEREST}

Authors have no conflict of interests, and this research did not receive any specific grant from funding agencies in the public, commercial, or not-for-profit sectors.

\section{REFERENCES}

1. The Ministry of Communications and Information Technology (MCIT). ICT facts and figures 2016. Available at: http://www.mcit.gov.eg/ Upcont/Documents/Reports\%20 and\%20 Documents 282016000 ICTFactsFigures 2016. pdf [Accessed 10 December 2016].

2. The Ministry of Communications and Information Technology (MCIT). ICT Indicators in Brief, September 2016 Monthly Issue. Available at: http://www.mcit.gov.eg/Upcont/Documents/ 
Publications_2112016000_ICT_Indicators September_2016_2_11_16En.pdf. [Accessed $1 \overline{0}$ December 2016].

3. eMarketing Egypt Online Competitiveness Intelligence report 2015. Available at: http:// www.dmc.ae/wp-content/uploads/2016/05/ ArabSocialMediaReport-2015.pdf. [Accessed 10 December 2016].

4. Subrahmanyam K, Šmahel D. The darker sides of the internet: violence, cyber bullying, and victimization. New York, NY: Digital Youth, Springer; 2011. 179-199.

5. Amichai-Hamburger Y, Hayat Z. The impact of the internet on the social lives of users: a representative sample from 13 countries. Comput Human Behav 2011; 27:585-589.

6. Tokunaga RS. Following you home from school: a critical review and synthesis of research on cyberbullying victimization. Comput Hum Behav $2010 ; 26: 277-287$.

7. Kowalski RM, Limber SP. Psychological, physical, and academic correlates of cyberbullying and traditional bullying. J Adolesc Health 2013; $53: 13-20$

8. Lindfors PL, Kaltiala-Heino R, Rimpelä $\mathrm{AH}$. Cyberbullying among Finnish adolescents - a population-based study. BMC Public Health 2012; $12: 1027$

9. Safaria T. Prevalence and impact of cyberbullying in a sample of Indonesian junior high school students. Turk Online J Edu Tech 2016; 15:82-91.

10. Craig W, Harel-Fisch Y, Pickett W. A crossnational profile of bullying and victimization among adolescents in 40 countries. Int J Public Health 2009; 54:216-224.

11. Bauman S. Cyberbullying in a rural intermediate school: an exploratory study. J Early Adolesc 2010; 30:803-833.

12. Bauman S, Newman ML. Testing assumptions about cyberbullying: perceived distress associated with acts of conventional and cyber bullying. Psychol Violence 2013; 3:27.

13. Beran T, Li Q. The relationship between cyberbullying and school bullying. J Stud Wellbeing 2007; 1:15-33.

14. Goebert D, Else I, Matsu C, Chung-Do J, Chang JY. The impact of cyberbullying on substance use and mental health in a multiethnic sample. Matern Child Health J 2011; 15:1282-1286.
15. Gradinger P, Strohmeier D, Spiel C. Traditional bullying, and cyberbullying: identification of risk groups for adjustment problems. J Psychol 2009; 217:205-213.

16. Juvonen J, Gross EF. Extending the school grounds? bullying experiences in cyberspace. J School Health 2008; 78:496-505.

17. Sourander A, BrunsteinKlomek A, Ikonen M, Lindroos $\mathrm{J}$, Luntamo $\mathrm{T}$, Koskelainen $\mathrm{M}$, et al. Psychosocial risk factors associated with cyberbullying among adolescents: a populationbase study. Arch Gen Psychiatry 2010; 67:720 728 .

18. Li Q. Bullying in the new playground: research into cyberbullying and cyber victimization. Australas J Educ Technol 2007; 23:435-454.

19. Akbulut Y, Eristi B. Cyberbullying and victimisation among Turkish university students. Australas J Educ Technol 2011; 27:1155-1170.

20. Elhawary S. Violence against women in Egyptby CAPMAS, Egypt, 2009. Available at: http:// unstats.un.org/unsd/demographic/meetings/vaw/ docs/Paper2.pdf. [Accessed 13 December 2016].

21. Ebaid N. Sexual harassment in Egypt: a neglected crime: an assessment for the Egyptian Government performance in regard to the sexual harassment in Egypt, 2013. Available at: http:// www.culturaldiplomacy.org/academy/content/ pdf/participant-papers/2013-05-iscd-hr/Neama Ebaid.pdf. [Accessed 13 December 2016].

22. Bridges A, Wosnitzer R. Aggression and sexual behavior in best-selling pornography: a content analysis update. International Communication Association 2007. Available at: http:// stoppornculture.org/about/about-the-issue/factsand-figures-2. [Accessed 13 December 2016].

23. Sticca F, Ruggieri S, Alsaker F, Perren S Longitudinal risk factors for cyberbullying in adolescence. J Comm Appl Socl Psych 2013; 23:52-67.

24. Marcum CD, Higgins GE, Freiburger TL, Ricketts ML. Battle of the sexes: An examination of male and female cyber bullying. Int J Cyber Criminol 2012; 6:904-911.

25. Smith PK, Mahdavi J, Carvalho M, Fisher S, Russell S, Tippett N. Cyberbullying: its nature and impact in secondary pupils. J Child Psychol Psychiatry 2008; 49:376-385. 
26. Saied SM, Elsabagh HM, El-Afandy AM. Internet and facebook addiction among Egyptian and Malaysian medical students: a comparative study, Tanta University, Egypt. Int J Community Med Public Health 2016; 3:1288-1297.

27. Fanti KA, Demetriou AG, Hawa VV. A longitudinal study of cyberbullying: examining risk and protective factors. Eur J Dev Psychol 2012; 9:168-181.

28. Haynie DL, Nansel T, Eitel P, Crump AD, Saylor $\mathrm{K}$, Yu K. Bullies, victims, and bully/victims: distinct groups of at-risk youth. J Early Adolesc $2001 ; 21: 29-49$.

29. Siegle D. Cyberbullying and sexting: technology abuses of the 21 st century. Gifted Child Today $2010 ; 33: 14-65$.

30. Hemphill S, Heerde J.Adolescent predictors of young adult cyber-bullying perpetration and victimization among Australian youth. J Adolesc Health. 2014; 55(4): 580-587.

31. Henry N, Powell A. Embodied harms: gender, shame, and technology-facilitated sexual violence. Violence Against Women 2015; 21:758-779.

32. Topçu Ç,Erdur-Baker Ö, Çapa-Aydin Y. Examination of cyberbullying experiences among Turkish students from different school types. Cyberpsychol Behav 2008; 11:643-648.

33. Wolak J, Mitchell KJ, Finkelhor D. Online victimization of youth: five years later. National
Center for Missing \& Exploited Children Bulletin; 2006. Available at: http://unh.edu/ccrc/pdf/ CV138.pdf. [Accessed 14 December 2016].

34. Patchin JW, Hinduja S. Bullies move beyond the schoolyard: a preliminary look at cyberbullying. Youth Violence Juv Justice 2006; 4:148-169.

35. Hinduja S, Patchin JW. Offline consequences of online victimization: school violence and delinquency. J Sch Violence 2007; 6:89-112.

36. Olenik-Shemesh D, Heiman T, Eden $\mathrm{S}$. Cyberbullying victimisation in adolescence: relationships with loneliness and depressive mood. Emotion Behav Difficult 2012; 17:361-374.

37. Price M, Dalgleish J. Cyberbullying experiences, impacts and coping strategies as described by Australian young people. Youth Stud Australia 2010; 29:51.

38. Jackson CL, Cohen R. Childhood victimization: modeling the relation between classroom victimization, cyber victimization, and psychosocial functioning. Psychol Pop Media Cult 2012; 1:254-269.

39. Larrañaga E, Yubero S, Ovejero A, Navarro R. Loneliness, parent-child communication and cyberbullying victimization among Spanish youths. Comput Hum Behav 2016; 65:1-8. 